19 Revue d'histoire du XIXe siècle

Société d'histoire de la révolution de 1848 et des

révolutions du XIXe siècle

$48 \mid 2014$

Usages du droit

\title{
Florence DEPREST, Élisée Reclus et l'Algérie colonisée
}

Paris, Belin, 2012, 142 p. ISBN : 978-2-7011-6407-6. 19,90 euros.

Stève Bessac-Vaure

\section{(2) OpenEdition}

Édition électronique

URL : http://journals.openedition.org/rh19/4697

DOI : $10.4000 /$ rh 19.4697

ISSN : $1777-5329$

Éditeur

La Société de 1848

Édition imprimée

Date de publication : 1 juin 2014

Pagination : 200-201

ISSN : 1265-1354

\section{Référence électronique}

Stève Bessac-Vaure, "Florence DEPREST, Élisée Reclus et l'Algérie colonisée », Revue d'histoire du XIXe siècle [En ligne], 48 | 2014, mis en ligne le 18 septembre 2014, consulté le 22 septembre 2020. URL : http://journals.openedition.org/rh19/4697 ; DOl : https://doi.org/10.4000/rh19.4697

Ce document a été généré automatiquement le 22 septembre 2020.

Tous droits réservés 


\title{
Florence DEPREST, Élisée Reclus et l'Algérie colonisée
}

Paris, Belin, 2012, 142 p. ISBN : 978-2-7011-6407-6. 19,90 euros.

\author{
Stève Bessac-Vaure
}

\section{RÉFÉRENCE}

Florence DEPREST, Élisée Reclus et l'Algérie colonisée, Paris, Belin, 2012, 142 p. ISBN :

978-2-7011-6407-6. 19,90 euros.

1 Après avoir publié une étude sur les Géographes en Algérie (1880-1950)ํㅜㄹ , Florence Deprest propose une monographie sur un géographe très particulier du fait de son engagement politique anarchiste, Élisée Reclus. Dans ce nouvel ouvrage, la professeure de géographie à l'université Paris 1 questionne le colonialisme de Reclus en mettant en garde contre tout anachronisme intellectuel ${ }^{2}$ et se demande ce qu'est une vision libertaire de la colonisation. Pour ce faire, elle s'appuie surtout sur la deuxième partie de L'Afrique septentrionale, onzième volume de la monumentale Nouvelle Géographie Universelle de Reclus.

2 Dans un premier chapitre, Florence Deprest montre que le «colonialisme » d'élisée Reclus découle à la fois de sa vision géographique et du "progressisme» contemporain ${ }^{3}$. Selon lui, la colonisation doit permettre de diffuser le progrès social grâce à « une mise en valeur rationnelle de l'espace terrestre et [au] développement d'une connexité généralisée au moyen du bateau à vapeur, du train et du télégraphe » (p.11). Florence Deprest souligne également que Reclus n'est pas exempt $\mathrm{d}^{\prime}$ ' orientalisme $»^{4}$ en reprenant à son compte un certain nombre de topoi ensuite érigés en arguments scientifiques, du fait de sa profession et de sa notoriété. Toutefois, le géographe français prône une assimilation à double-sens et souligne les mérites de l'islam qui permet parfois de lutter contre l'esclavage.

Dans un deuxième temps, l'auteure étudie la "méditerranéisation » (Ian Morris) dans l'œuvre d'Élisée Reclus. L'Algérie est sinon intégrée du moins rapprochée de l'Europe. 
Le géographe anarchiste évoque un milieu homogène de part et d'autre de la Méditerranée, soulignant davantage les continuités que les discontinuités. Ainsi, l'Afrique du Nord fait partie, selon lui, de l'« aire méditerranéenne ». Il perçoit alors la colonisation comme un phénomène logique et pérenne : «quoiqu'on ait souvent répété le contraire, l'annexion politique de l'Algérie à l'Europe est un fait désormais acquis de l'histoire $»^{5}$. Reclus va plus loin en considérant qu'au sein de cette aire géographique existe une culture propre, culture à laquelle appartiendraient les Kabyles, tandis que les Arabes seraient un élément exogène. Le géographe français contribue donc à ce que Charles-Robert Ageron a qualifié de " mythe kabyle».

Enfin, dans un dernier chapitre, Florence Deprest cherche à démontrer qu'Élisée Reclus dénonce les violences de la "pacification". Bien que nous ne puissions pas suivre l'auteure lorsqu'elle écrit que "pour le public français de l'époque, une telle énonciation [le massacre d'un village algérien] est déjà une dénonciation » (p. 82) puisque de nombreux auteurs - dont des militaires ayant commis ces massacres - les évoquent publiquement sans la moindre intention dénonciatrice, il est indéniable que Reclus condamne les violences perpétrées par les militaires. Ceci est d'ailleurs probablement lié à son antimilitarisme anarchiste. Cependant, il est favorable à la colonisation agraire, à laquelle participe son gendre.

Élisée Reclus est donc pris dans une tension irréconciliable entre l'anarchiste qui soutient les peuples en lutte et le géographe du XIX ${ }^{e}$ siècle qui voit dans cette colonisation agraire, de peuplement, un progrès. Par ailleurs, cet ouvrage, qui encourage le dialogue pluridisciplinaire, invite les historiens de la période coloniale à s'intéresser aux travaux des géographes. Ceux-ci peuvent permettre d'avoir une autre perception des réalités coloniales, fournir d'autres sources à l'instar des croquis de Reclus, reproduits dans le livre.

\section{NOTES}

1. Florence Deprest, Géographes en Algérie (1880-1950). Savoirs universitaires en situation coloniale, Paris, Belin, 2009.

2. Cf. notamment Antoine Lilti, «Rabelais est-il notre contemporain? Histoire intellectuelle et herméneutique critique ", Revue d'histoire moderne et contemporaine, $\mathrm{n}^{\circ}$ 59-4bis, 2012, p. 65-84.

3. Cette notion de "progrès", introduite par la colonisation, et son corollaire, la "mission civilisatrice ", commencent à être remises en question par certains anticolonialistes dès les années 1880. Sur ce point, $c f$. Jean-Pierre Biondi et Gilles Morin, Les anticolonialistes (1881-1962), Paris, Robert Laffont, 1992 et Claude Liauzu, Histoire de l'anticolonialisme en France, Paris, Pluriel,

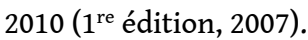

4. Edward Said, L'Orientalisme. L'Orient créé par l'Occident, Paris, le Seuil, 1980 (1 ${ }^{\text {re }}$ édition en anglais, Orientalism, 1978).

5. Élisée Reclus, Nouvelle Géographie Universelle, tome XI, p. 300, cité p. 59. 